\title{
A Kinetic Approach of DPPH Free Radical Assay of Ferulate-Based Protic Ionic Liquids (PILs)
}

\author{
Nur Afiqah Ahmad ${ }^{1}$, Khairulazhar Jumbri 1,2,*®D, Anita Ramli ${ }^{1}$, Noraini Abd Ghani ${ }^{1,2}$, \\ Haslina Ahmad ${ }^{3}$ and Jun Wei Lim ${ }^{1}$ (D) \\ 1 Department of Fundamental and Applied Sciences, Universiti Teknologi PETRONAS, Seri Iskandar 32610, \\ Perak, Malaysia; nurafiqahahmad306@gmail.com (N.A.A.); anita_ramli@utp.edu.my (A.R.); \\ noraini.ghani@utp.edu.my (N.A.G.); junwei.lim@utp.edu.my (J.W.L.) \\ 2 Centre of Research in Ionic Liquids (CORIL), Universiti Teknologi PETRONAS, \\ Seri Iskandar 32610, Perak, Malaysia \\ 3 Department of Chemistry, Faculty of Science, Universiti Putra Malaysia, UPM Serdang 43400, \\ Selangor, Malaysia; haslina_ahmad@upm.edu.my \\ * Correspondence: khairulazhar.jumbri@utp.edu.my; Tel.: +60-5368-7843
}

Academic Editor: Werner Bonrath

Received: 24 October 2018; Accepted: 16 November 2018; Published: 5 December 2018

\begin{abstract}
The antiradical efficiency (AE) and kinetic behavior of a new ferulate-based protic ionic liquids (PILs) were described using 2,2-diphenyl-1-picrylhydrazyl (DPPH) free radical assay. The reduction of the DPPH free radical (DPPH•) was investigated by measuring the decrease in absorbance at $517 \mathrm{~nm}$. The time to reach steady state for the reaction of parent acid (ferulic acid) and synthesized PILs with DPPH• was continuously recorded for $1 \mathrm{~h}$. Results revealed that the AE of 2-butylaminoethanol ferulate (2BAEF), 3-dimethylaminopropanol ferulate (3DMAPF) and 3-diethylaminopropanol ferulate (3DEAPF) PILs have improved compared to ferulic acid (FA) as the reaction class changes from low to medium. This attributed to the strong hydrogen abstraction occurred in the PILs. Furthermore, these PILs were found to have a good kinetic behavior compared to FA due to the high rate constant $\left(k_{2}\right)\left(164.17,242.84\right.$ and $244.73 \mathrm{M}^{-1} \mathrm{~s}^{-1}$, respectively). The alkyl chain length and more alkyl substituents on the nitrogen atom of cation were believed to reduce the cation-anion interaction and speed up the hydrogen atom transfer (HAT) and electron transfer (ET) mechanisms; hence, increased rate constant was observed leading to a strong antioxidant activity of the synthesized PILs.
\end{abstract}

Keywords: protic ionic liquids; antioxidant; DPPH radical scavenging; kinetic; antiradical efficiency

\section{Introduction}

Phenolic compounds are secondary metabolites that exist in plant tissue. Typically, these compounds act as an antioxidant in a biological system as their ability is to reduce oxidative-stress resulting in chronic disease [1]. The two major classes of phenolic compounds are flavonoid and non-flavonoids [2]. Phenolic acids are the most natural non-flavonoid antioxidants highly found in plants. They had been widely used in health, cosmetics, food and pharmaceutical industries [3-6] due to their competent biological properties such as antioxidant, anti-cancer, anti-carcinogenic or anti-mutagenic, anti-bacterial, anti-viral and anti-inflammatory [7-11]. Phenolic acids were derived from two major derivatives known as benzoic and cinnamic acid. Both derivatives were distinguished based on the structure of their compounds [12].

Ferulic acid (FA) is a chemical compound derived from a cinnamic acid derivative. This compound is usually found in herbal medicines and plants [13]. Besides, FA is a phenolic acid with low toxicity since it is easy to be absorbed and metabolized by the human body [14]. Moreover, this compound 
is commonly used in food, pharmaceutical and cosmetic products due to its strong antioxidant properties $[15,16]$. Furthermore, it has been reported to have other several biological properties such as anti-inflammatory, antimicrobial, anticancer, anti-diabetes and anti-neurodegenerative [17-19]. On top of that, this compound is very reactive towards reactive oxygen species (ROS), lipid oxidation and 2,2-diphenyl-1-picrylhydrazyl (DPPH) free radical [20].

From the previous study, several methods have been applied for assessing the antioxidant activity of a compound. For instance, oxygen radical absorbance capacity (ORAC), total radical antioxidant parameter (TRAP), ferric reducing antioxidant power (FRAP), Cupric reducing antioxidant power (CUPRAC), lipid peroxidation, 2,2'-azinobis(3-ethylbenzthiazoline-6-sulfonic acid (ABTS) and 2,2-diphenyl-1-picrylhydrazyl (DPPH) radical scavenging assay [21-24].Nevertheless, the DPPH radical scavenging assay is the most common method used due to its stable, easy to perform and commercial availability compared to other methods [25]. This assay was based on the principle of reduction of DPPH free radical by accepting a hydrogen atom from the scavenger compound; hence, the color was seen changing from violet to yellow [26,27]. The DPPH free radical is classified as a naturally stable nitrogen radical that might have a different reaction kinetic with antioxidant compounds [28].

The kinetic reaction of the antioxidant compound is really important as the free radical has a short half-life [29]. Indeed, most studies have focused on the kinetic behavior of compounds to determine their effective antioxidants [30-32]. Recently, modifications on phenolic acid in the form of ionic liquids (ILs) have increased its popularity. This is because ILs were known as a tuneable compound where their properties can be tuned according to the types of cation and anion used [33]. Czerniak et al. synthesized gallate-based ILs to enhance the performance of the antioxidant. From their finding, the antioxidant activity of the synthesized ILs were seen affected by the intermolecular hydrogen bond that present due to the linear chain and stearic effect of the structure [34]. The same research group has then studied the dicationic based ILs and found that as the number of the active group increases on the structure, the antioxidant activity of the synthesized compound increased [35]. Furthermore, there is another study reporting the abietate-based ILs. However, the antioxidant activity was only focused on the measurement of the $\mathrm{EC}_{50}$ of the synthesized compound [36]. Therefore, in this work, five new ferulate-based PILs were synthesized to enhance the performance of antioxidant. Apart from calculating the $\mathrm{EC}_{50}$, antiradical efficiency $(\mathrm{AE})$ and rate constant of the synthesized PILs were also discussed to determine the effective PILs toward DPPH free radical (DPPH•).

\section{Results and Discussion}

The antioxidant activity of the synthesized PILs, which are 2-methylaminoethanol ferulate (2MAEF), 2-propylaminoethanol ferulate (2PAEF), 2-butylaminoethanol ferulate (2BAEF), 3-dimethylaminopropanol ferulate (3DMAPF) and 3-diethylaminoethanol ferulate (3DEAPF) was determined by calculating the $\mathrm{EC}_{50}, \mathrm{TEC}_{50}$, antiradical efficiency $(\mathrm{AE})$ and rate constant $\left(k_{2}\right)$.

\section{1. $E C_{50}$}

$\mathrm{EC}_{50}$ is the maximum concentration needed to reduce half of the DPPH free radical (DPPH•) at steady state, which is known as half-maximal effective concentration. Figure 1a-1f depict the reaction between $60 \mu \mathrm{M}$ DPPH $\bullet$ with different concentrations of FA and PILs. The percentage of remaining $\mathrm{DPPH} \bullet$ was rapidly decreased as the concentration of FA and PILs increases. Increase in concentration will also increase the total number of molecules. Hence, the scavenging activity of the active compound was increased due to the presence of more active groups in the reaction medium [37]. 

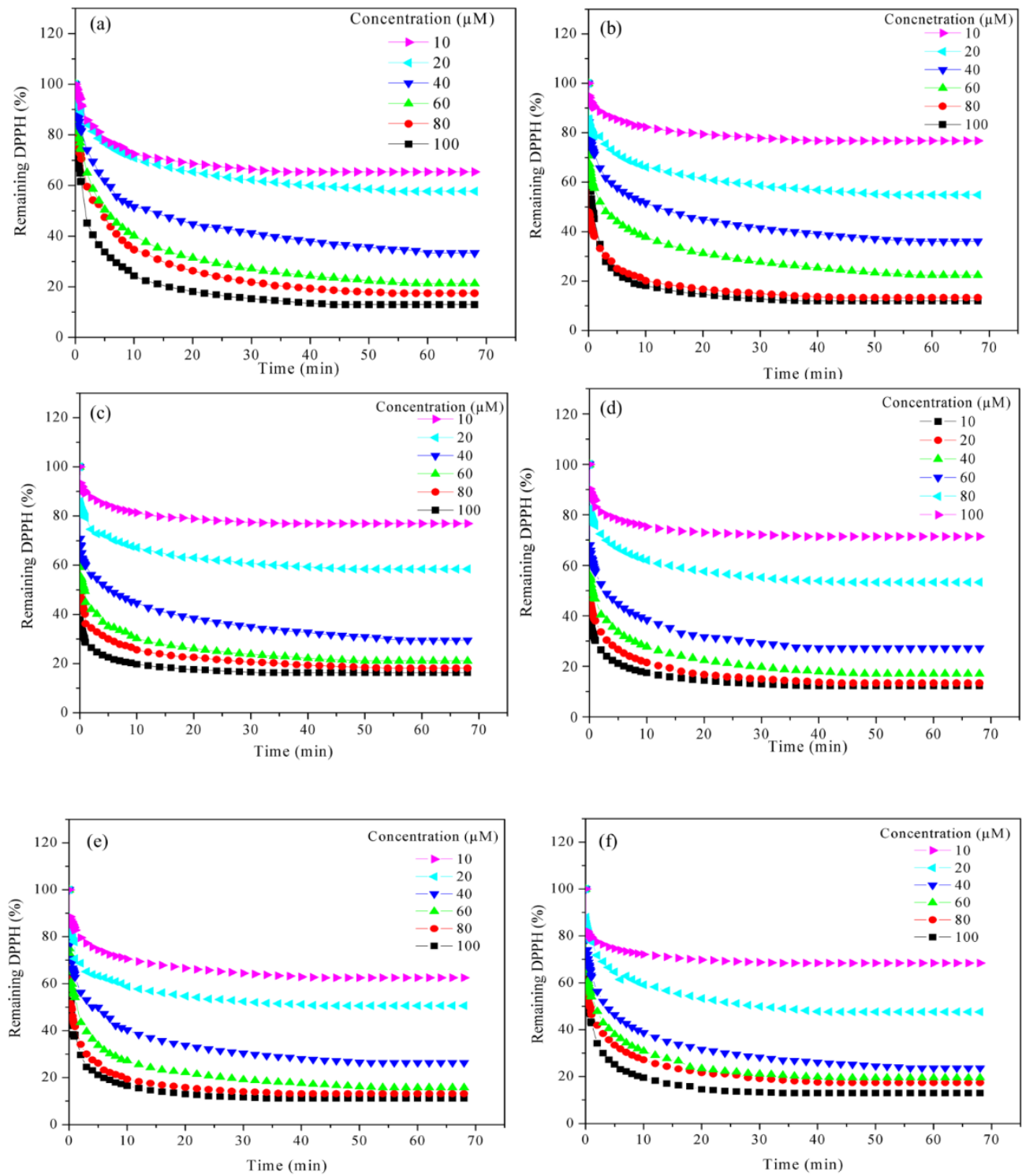

Figure 1. Reaction kinetic between $60 \mu \mathrm{M}$ of DPPH• and different concentration FA and synthesized PILs: (a) FA; (b) 2MAEF; (c) 2PAEF; (d) 2BAEF; (e) 3DMAPF; (f) 3DEAPF.

The effective antioxidant activity of the synthesized PILs and FA was determined by measuring the $\mathrm{EC}_{50}$. The $\mathrm{EC}_{50}$ was calculated to express the scavenging ability of $50 \% \mathrm{DPPH} \bullet$ at steady state (Figures S1-S6). The compound with lower $\mathrm{EC}_{50}$ will exhibit higher and good antioxidant activity. The summarized results in Table 1 demonstrate that the synthesized PILs being a more potent antioxidant as the $\mathrm{EC}_{50}$ was ranging from $18.40 \pm 0.12 \mu \mathrm{M}$ to $25.00 \pm 0.20 \mu \mathrm{M}$, which is lower than $\mathrm{FA}$ $(26.00 \pm 0.10 \mu \mathrm{M})$. This was believed to occur due to the presence of the extra active groups (-OH and -NH) on the cation and anion structure of PILs [38]. The active group will help to neutralize the radical on the nitrogen atom of the DPPH• by transferring of hydrogen atom via hydrogen abstraction process [39]. 
Table 1. Parameters of radical scavenging activity of parent acid (FA) and synthesized PILs: $\mathrm{EC}_{50}(\mu \mathrm{M})$, $\mathrm{TEC}_{50}$ and antiradical efficiency, $\mathrm{AE}\left(\times 10^{-3}\right)$

\begin{tabular}{ccccc}
\hline Sample & $\mathbf{E C}_{\mathbf{5 0}}(\boldsymbol{\mu M})$ & TEC $_{\mathbf{5 0}}$ & Antiradical Efficiency, AE $\left(\times \mathbf{1 0}^{-\mathbf{3}}\right)$ & Reference \\
\hline FA & $24.7 \pm 0.40$ & 53 & $0.80 \pm 0.00$ & {$[40]$} \\
FA & $26.0 \pm 0.10$ & 56 & $0.70 \pm 0.05$ & This work \\
2MAEF & $25.0 \pm 0.20$ & 53 & $0.75 \pm 0.15$ & This work \\
2PAEF & $24.3 \pm 0.14$ & 50 & $0.82 \pm 0.05$ & This work \\
2BAEF & $22.0 \pm 0.17$ & 45 & $1.01 \pm 0.08$ & This work \\
3DMAPF & $20.4 \pm 0.05$ & 44 & $1.11 \pm 0.03$ & This work \\
3DEAPF & $18.4 \pm 0.12$ & 42 & $1.29 \pm 0.07$ & This work \\
\hline
\end{tabular}

The $\mathrm{EC}_{50}$ of the synthesized five ferulate-based PILs was seen only slightly different since all of them have the same number of active groups attached on the ion-pair structure. However, the order of the reactivity was increased from $2 \mathrm{MAEF}<2 \mathrm{PAEF}<2 \mathrm{BAEF}<3 \mathrm{DMPAF}<3 \mathrm{DEAPF}$ with the $\mathrm{EC}_{50}$ of $25.00 \pm 0.20,24.30 \pm 0.14,22.00 \pm 0.17,20.40 \pm 0.05$ and $18.40 \pm 0.12 \mu \mathrm{M}$, respectively. The low presence of $\mathrm{DPPH} \bullet$ at steady state was expected to affect the reactivity since the percentage remaining $\mathrm{DPPH} \bullet$ at steady state also depends on the ability of the compound to transfer the hydrogen atom in a fast manner, thus leading to the decrease of concentration needed to scavenge $50 \%$ of DPPH• $\left(\mathrm{EC}_{50}\right)$. This is further discussed in the next section $\left(\mathrm{TEC}_{50}\right)$.

\section{2. $T E C_{50}$}

The time to reach the steady state $\left(\mathrm{TEC}_{50}\right)$ was considered to determine the antioxidant effect of the tested compound. The faster the reaction reaches a steady state, the more efficient is the antioxidant. The calculation of TEC $_{50}$ shows in Figures S7-S12. According to a previous study, the FA was classified as a medium reaction since the time needed to reach a steady state is around $30 \mathrm{~min}$ to $1 \mathrm{~h} \mathrm{[41]}$. From Table 1, the TEC 50 of FA ( $56 \mathrm{~min}$ ) did not differ greatly with the synthesized PILs (44-53 min), whereas the class of reaction remained unchanged.

Moreover, the selection of quaternary-ammonium cation had caused a slow diffusion of PILs due to the narrow-like shape or bulky structure in the substitution of an alkyl group at the nitrogen atom. Tokuda et al. examined the diffusion coefficient between the aromatic-cation based and quaternary-ammonium cation based ILs [42]. From their findings, the aromatic-cation based ILs had shown a larger diffusion coefficient $\left(15.0 \times 10^{-7} \mathrm{~cm}^{2} \mathrm{~s}^{-1}\right)$ than the quaternary-ammonium cation based $\left(9.3 \times 10^{-7} \mathrm{~cm}^{2} \mathrm{~s}^{-1}\right)$ as the presence of aromatic ring led to the formation of broad-like shape and fast diffusion of ion to occur easily [43]. Since the transfer of hydrogen atom is diffusion controlled reaction, the slow diffusion of quaternary-ammonium cation had affected the $\mathrm{TEC}_{50}$ of synthesized PILs [44].

However, in the case of cation structure, $[2 \mathrm{BAE}]^{+},\left[^{3 \mathrm{DMAP}}\right]^{+}$and $[3 \mathrm{DEAP}]^{+}$need lesser time to react with the DPPH• than $[2 \mathrm{MAE}]^{+}$and $[2 \mathrm{PAE}]^{+}(45,44,42,50$, and $53 \mathrm{~min}$, respectively). The increase in alkyl chain length and more alkyl substituent on the nitrogen atom of the cation structure caused the formation of a more flexible structure that can reduce the strength of intermolecular hydrogen bond between the ion pairs and the effect of steric hindrance, thus allowing a fast transfer of hydrogen atom and increasing the scavenging activity of DPPH $\bullet$. Furthermore, both [2MAE $]^{+}$and $[2 \mathrm{PAE}]^{+}$ have a small and rigid structure with high tendency to form a strong hydrogen bond with the solvent (methanol) and ferulate anion $[\mathrm{F}]^{-}$, which led to a slow release of hydrogen atom of -NH group [44]. The cation and anion structure of synthesized PILs shows in Figure 2. 


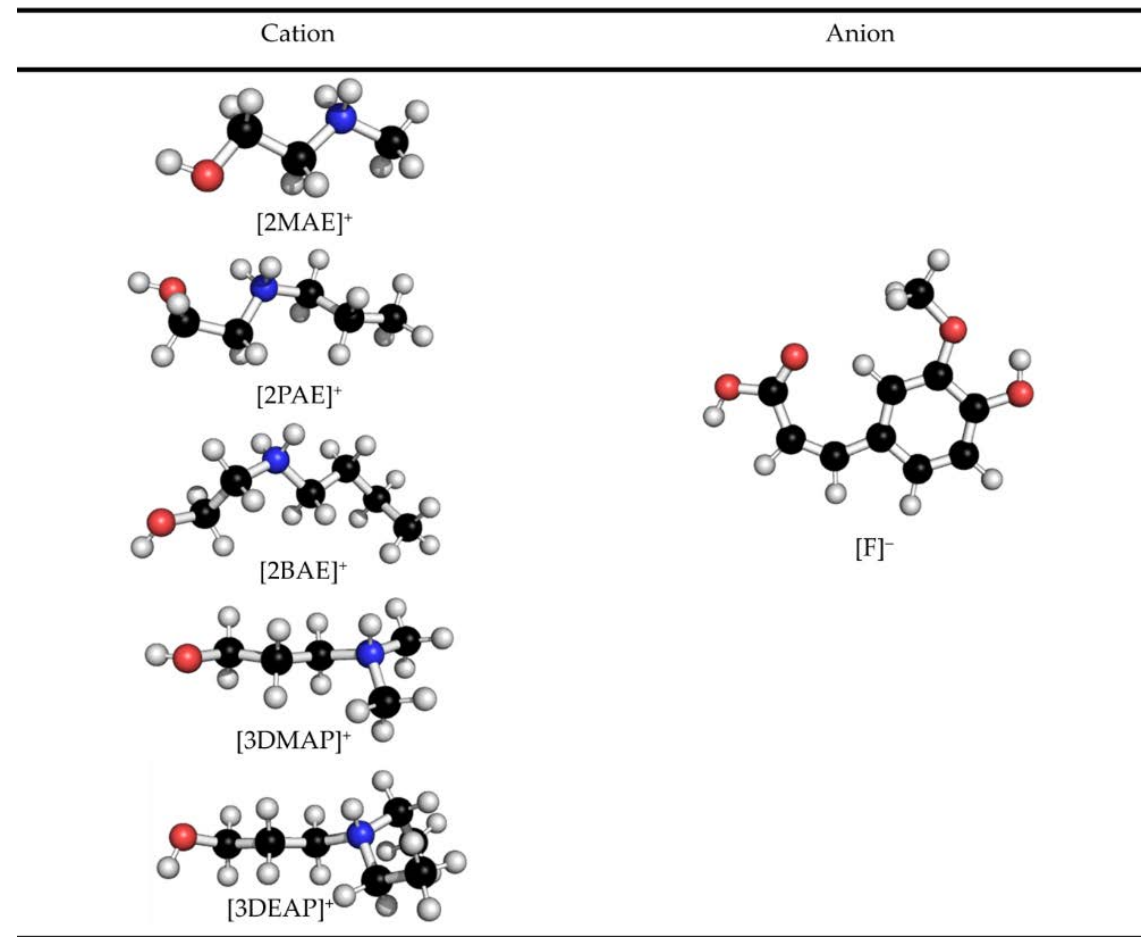

Figure 2. Cation and anion structure of the synthesized PILs.

\subsection{Antiradical Efficiency (AE)}

The antiradical efficiency (AE) is the significant parameter measured to determine the effectiveness of antioxidant activity. This parameter is a kinetic-based study as the measurement comprised the potency $\left(\mathrm{EC}_{50}\right)$ and the reaction time $\left(\mathrm{TEC}_{50}\right)$. The $\mathrm{AE}$ was calculated using the formula in the Equation (1)

$$
A E=\frac{1}{E C_{50} \times T E C_{50}}
$$

Based on the formula given, the lower $\mathrm{EC}_{50}$ and $\mathrm{TEC}_{50}$ will give a higher $\mathrm{AE}$. Table 1 shows that the AE of synthesized PILs was ranged from $0.75 \pm 0.15$ to $1.29 \pm 0.07 \mu \mathrm{M}$, which is higher than the FA $(0.70 \pm 0.05 \mu \mathrm{M})$. A higher AE indicates a more efficient antioxidant due to the higher reactivity of active group with the DPPH•. This is expected to occur because of the presence of the extra active group and fast reaction. According to the AE classification (Table 2) [45], the AE of the compound followed the order of $3 \mathrm{DEAPF} \geq 3 \mathrm{DMAPF} \geq 2 \mathrm{BAEF}>2 \mathrm{PAEF} \geq 2 \mathrm{MAEF}>\mathrm{FA}$. The class of the AE was slightly enhanced from low to medium class as the alkyl chain length and substituent of the cation structure increase. The short alkyl chain length and more hydrogen substituents on the nitrogen atom of cation formed a small structure of PILs that can enhance the presence of the PILs molecules in the reaction system. Hence, promote to random molecular packing that reduced the accessibility to DPPH• due to the crowding effect of PILs molecules around the DPPH• molecules [46]. Moreover, the changes in the classes may be reflected by the fast rate of reaction, which is very important in biological system since the free radical only has a short lifetime [29].

Table 2. Classification of antiradical efficiency (AE) for antioxidant compound.

\begin{tabular}{cc}
\hline Classification & Value AE \\
\hline Low & $\mathrm{AE} \leq 1.0 \times 10^{-3}$ \\
Medium & $1.0 \times 10^{-3}<\mathrm{AE} \leq 5.0 \times 10^{-3}$ \\
High & $5.0 \times 10^{-3}<\mathrm{AE} \leq 10.0 \times 10^{-3}$ \\
Very high & $\mathrm{AE}>10.0 \times 10^{-3}$ \\
\hline
\end{tabular}




\subsection{Stoichiometry of Reaction}

The stoichiometric is the amount of antioxidant needed to reduce $100 \%$ of DPPH• in which the value was calculated by multiplying the $\mathrm{EC}_{50}$ (in molar ratio) with 2 and the inverse values indicating the moles of DPPH• were reduced by $1 \mathrm{~mol}$ of antioxidant [41,47]. This parameter is also known as a stoichiometric factor $(n)$ and was calculated to determine the kinetic behavior of the compound. The $n$ of FA (Table 3) was seen in agreement with the value obtained by Brand-Williams et al. [47]. As predicted, the $n$ value of PILs was higher than FA since the value was calculated from the $\mathrm{EC}_{50}$. However, the number of active group present on the structure was negligible as the $n$ value was affected by the structure reactivity. This has been proven by the findings of Xie et al. in their study on the correlation of initial rate with stoichiometry [46].

Table 3. Stoichiometric factor of FA and PILs calculated from the $\mathrm{EC}_{50}$ value.

\begin{tabular}{ccc}
\hline Sample & EC $_{\mathbf{5 0}}(\boldsymbol{\mu m o l}$ of Antioxidant $/ \boldsymbol{\mu m o l}$ of DPPH) & Stoichiometric Factor $(\boldsymbol{n})^{\mathbf{1}}$ \\
\hline FA & $0.43\left(0.42^{2}\right)$ & 1.20 \\
2MAEF & 0.41 & 1.22 \\
2PAEF & 0.40 & 1.25 \\
2BAEF & 0.36 & 1.39 \\
3DMAPF & 0.33 & 1.52 \\
3DEAPF & 0.30 & 1.67 \\
\hline \multicolumn{3}{c}{}
\end{tabular}

\subsection{Kinetic Behaviour of PILs Towards DPPH•}

Fast initiate step of synthesized PILs and FA towards DPPH• was determined to study the effectiveness of the antioxidant. Generally, the DPPH $\bullet$ reacts with the antioxidant compound ( $\mathrm{ArOH})$ via two different reaction mechanisms. The first mechanism is called hydrogen transfer (HAT), which is a direct abstraction of hydrogen atom reaction. The second mechanism is the electron transfer reaction (ET) from $\mathrm{ArOH}$ or its anion $\left(\mathrm{ArO}^{-}\right)$to $\mathrm{DPPH} \bullet$ which also known as electron abstraction [27]. The scavenging activity is represented by the equation as follows:

(1) HAT mechanism

$$
\begin{gathered}
\mathrm{ArOH}+\mathrm{DPPH} \bullet \rightarrow \mathrm{ArO} \bullet+\mathrm{H}-\mathrm{DPPH} \\
\operatorname{ArO} \bullet+\mathrm{DPPH} \bullet \rightarrow \text { product }
\end{gathered}
$$

This mechanism neutralized the DPPH• by directly reacting with the antioxidant compound to form radical of phenolic antioxidant. In the reaction the bond dissociation energy (BDE) had affected HAT mechanism.

(2) ET mechanism

$$
\begin{aligned}
\mathrm{ArOH}+\mathrm{X} \bullet & \rightarrow \mathrm{ArOH} \bullet^{+}+\mathrm{X}^{-} \\
\mathrm{ArOH} \bullet & \rightarrow \mathrm{ArO} \bullet+\mathrm{H}^{+}
\end{aligned}
$$

The ET mechanism has two-step reaction in which the first step involved the formation of phenolic cationic radical and an anionic compound. Then, in the second step, the antioxidant was decomposed into phenolic radical and proton [27]. This mechanism depends on the ionization potential (IP).

The kinetic reaction of scavenging DPPH $\bullet$ is depend on the relative concentration of reactants [41]. In the present study the concentration of DPPH $\bullet$ and PILs was considered. Since the concentration of $\mathrm{DPPH} \bullet$ was fixed at $60 \mu \mathrm{M}$, the reaction followed the pseudo-first order as the increasing concentration of PILs and FA in the reaction medium was in a large excess. The reaction was defined as

$$
-\frac{d[\mathrm{DPPH} \bullet]}{d t}=k_{1}[\mathrm{DPPH} \bullet]
$$


$k_{1}$ is the rate constant obtained from the slope of non-linear pseudo first order (Figure 3). The equation was written as:

$$
A=A_{0} e^{-k_{1} t}
$$

where $A$ is the DPPH $\bullet$ concentration, $t$ is time and $A_{0}$ represents DPPH $\bullet$ concentration at $t=0$. The $k_{1}$ is rate constant.

Therefore, the rate of reaction was respected to the concentration of DPPH•.

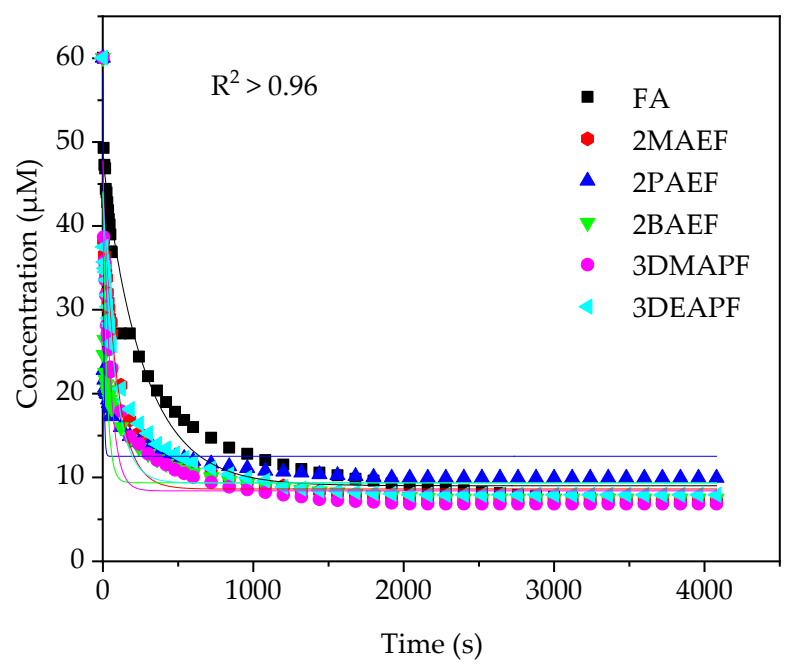

Figure 3. Curve fitting of pseudo first order rate constant $\left(k_{1}\right)$ of synthesized PILs and FA.

However, the $k_{1}$ value was also depended on concentration of PILs. Thus, the rate of DPPH• scavenging could be defined as

$$
-\frac{d[\mathrm{DPPH} \bullet}{d t}=k_{1}[\mathrm{DPPH} \bullet]=n k_{2}[\mathrm{DPPH} \bullet][\mathrm{ArOH}]
$$

$n$ correspond to the stoichiometric factor of $\mathrm{ArOH}$ and $k_{2}$ is the rate constant. By considering the stoichiometric factor $(n), k_{2}$ value was calculated from the equation written as

$$
k_{2}=\frac{k_{1}}{n[\mathrm{ArOH}]}
$$

Table 4 shows that the 2BAEF, 3DMAPF and 3DEAPF were found to have a higher rate constant $\left(k_{2}\right)\left(164.17,242.84\right.$ and $244.73 \mathrm{M}^{-1} \mathrm{~s}^{-1}$, respectively) than FA $\left(109.48 \mathrm{M}^{-1} \mathrm{~s}^{-1}\right)$. However, another two PILs (2MAEF and 2PAEF) has shown lower reaction towards DPPH• as they have lower $k_{2}$ (86.89 and $107.20 \mathrm{M}^{-1} \mathrm{~s}^{-1}$ ). The structure-activity relationship (SAR) was suggested to affect the $k_{2}$ of the synthesized PILs and FA because the different structure will react differently to scavenge the $\mathrm{DPPH} \bullet$ [48]. Furthermore, in this study, the different cation structure was predicted to influence the rate constant of PILs. As previously discussed, the rate constant was controlled by the HAT and ET mechanisms. Klein et al. reported that the mechanism of the antioxidant amine type structure (-NH) relies upon the N-H bond dissociation energy (BDE) and ionization potential (IP) [49]. They concluded that the BDE and IP of N-H bond are highly dependent on substituent group. Lalevee et al. 2002 reported the trend of the BDE for amine group. From their finding, the strength of the BDE decreased as the bulkiness and $N$-alkylation of the amine group increases. This indicates the formation of stable aminyl radical from $\sigma \mathrm{C}-\mathrm{C}$ bond by hyperconjugation reaction [50]. For instance, 3DMAPF and 3DEAPF were found to have strong reactivity compared to 2MAEF, 2PAEF and 2BAEF. This corresponds to the alkyl substituent on the nitrogen atom that reduced the BDE and IP as weak intramolecular hydrogen bond occurred between the nitrogen and hydrogen atom of -NH group. Besides, the lower rate constant 
of 2MAEF and 2PAEF was observed due to the strong intermolecular interaction between the ion pairs leading to compact structure, thus hindering the radical scavenging of the $-\mathrm{OH}$ and $-\mathrm{NH}$ group on PILs [51]. The calculated $k_{2}$ of FA were in agreement with previous work [52]

Table 4. Rate constant, $k_{2}\left(\mathrm{M}^{-1} \mathrm{~s}^{-1}\right)$ and stoichiometric factor $(n)$ for reaction medium of DPPH• $(60 \mu \mathrm{M})$ and $100 \mu \mathrm{M}$ of FA or synthesized PIL.

\begin{tabular}{ccc}
\hline Sample & Stoichiometric Factor $(\boldsymbol{n})$ & $\boldsymbol{k}_{\mathbf{2}}\left(\mathbf{M}^{\mathbf{- 1}} \mathbf{s}^{\mathbf{- 1}}\right)$ \\
\hline FA & 1.16 & 109.48 \\
2MAEF & 1.22 & 86.89 \\
2PAEF & 1.25 & 107.20 \\
2BAEF & 1.39 & 164.17 \\
3DMAPF & 1.51 & 242.84 \\
3DEAPF & 1.67 & 244.73 \\
\hline
\end{tabular}

\section{Materials and Methods}

\subsection{Materials}

Ferulic acid (FA, purity 98\%) and 3-diethylamino-1-propanol (3DEAP, purity 98\%) were purchased from Across (Shah Alam, Malaysia). 2,2-diphenyl-1-picrylhydrazyl (DPPH, purity 95\%), 2-(propylamino)ethanol (2PAE, purity, 96\%) and methanol were supplied by Sigma Aldrich (Darmstadt, Germany). 2-(Methylamino)ethanol (2MAE, purity 98\%), 2-(Butylamino)ethanol (2BAE, purity 98\%) and 3-dimethylamino-1-propanol (3DMAP, purity 99\%) were all purchased from Merck (Darmstadt, Germany). All chemicals were used as received without further purification.

\subsection{Synthesis of PILs}

The PILs were synthesized by mixing an equimolar of parent acid (FA) with five different alkanolamine bases (2MAE, 2PAE, 2BAE, 3DMAP and 3DEAP) through neutralization reaction. A $6.9 \mathrm{~g}$ of FA ( $0.05 \mathrm{~mol}$, in excess) was dissolved with $50 \mathrm{~mL}$ hot distillate water in $100 \mathrm{~mL}$ two necks round bottom flask equipped with a reflux condenser and the solution was stirred vigorously. Excess of FA was used to make sure the neutralization reaction occurs completely. Then, an equimolar of the base was slowly introduced into to the FA solution. The mixture was then stirred for $24 \mathrm{~h}$ and the unreacted acid was removed by filtration. The water was removed by using rotatory evaporator at $50{ }^{\circ} \mathrm{C}$ (60 mbar) for $5 \mathrm{~h}$. Then, the synthesized PILs were further dried under vacuum for overnight. All PILs were successfully characterized by using NMR (Selangor, Malaysia), FTIR (Kyoto, Japan), LC-MS (Bayan Lepas, Penang, Malaysia), and thermal analysis (Kyoto, Japan).

\subsection{Preparation of Stock Solution}

The five-ferulate based PILs which are 2-methylaminoethanol ferulate (2MAEF), 2-propylaminoethanol ferulate (2PAEF), 2-butylaminoethanol ferulate (2BAEF), 3-dimethylaminopropanol ferulate (3DMAPF) and 3-diethylaminoethanol ferulate (3DEAPF), were successfully synthesized through neutralization reaction method. Afterwards, $20 \mathrm{mM}$ of synthesized PILs was prepared in methanol solution followed by serial dilution into six lower concentrations $(100,80,60,40,20$ and $10 \mathrm{mM}$ ) using $10 \mathrm{~mL}$ of volumetric flask. The final concentration of PILs after added into the DPPH solution was ranging from 10 to $100 \mu \mathrm{M}$. For the free radical stock solution, $2.37 \mathrm{mg}$ of DPPH was dissolved in a methanol and diluted into $100 \mathrm{~mL}$ of volumetric flask to prepare $60 \mu \mathrm{M}$ of DPPH solution. As a precaution step, the solution was freshly prepared and kept in a dark condition at ambient temperature during the analysis. 


\subsection{DPPH free Radical Assay}

The modified 2,2-diphenyl-1-picrylhydrazyl (DPPH) free radical assay has followed the method determined by Brand-Williams et al. [47]. Based on this assay, the color change of DPPH solution (in methanol) from violet to yellow was observed using Thermo Fisher UV-Vis spectrometer (Waltham, MA, USA) by measuring the change of absorbance at a wavelength $517 \mathrm{~nm}$. The yellow color indicated the reduction of DPPH free radical (DPPH•). Basically, a $3000 \mu \mathrm{L}$ of DPPH solution with a concentration of $60 \mu \mathrm{M}$ was pipetted into a quartz cuvette with the initial absorbance measured. Afterwards, $30 \mu \mathrm{L}$ of the synthesized PILs with varied final concentration (10-100 $\mu \mathrm{M})$ was added and mixed rapidly. Then, the decrease in absorbance was recorded every $5 \mathrm{~s}$ for $10 \mathrm{~min}$ and continued for every $2 \mathrm{~min}$ until it reaches a steady state (around $1 \mathrm{~h}$ ). The exact concentration of DPPH• in the reaction medium was determined from a calibration curve (Figure 4) with a linear regression as follows:

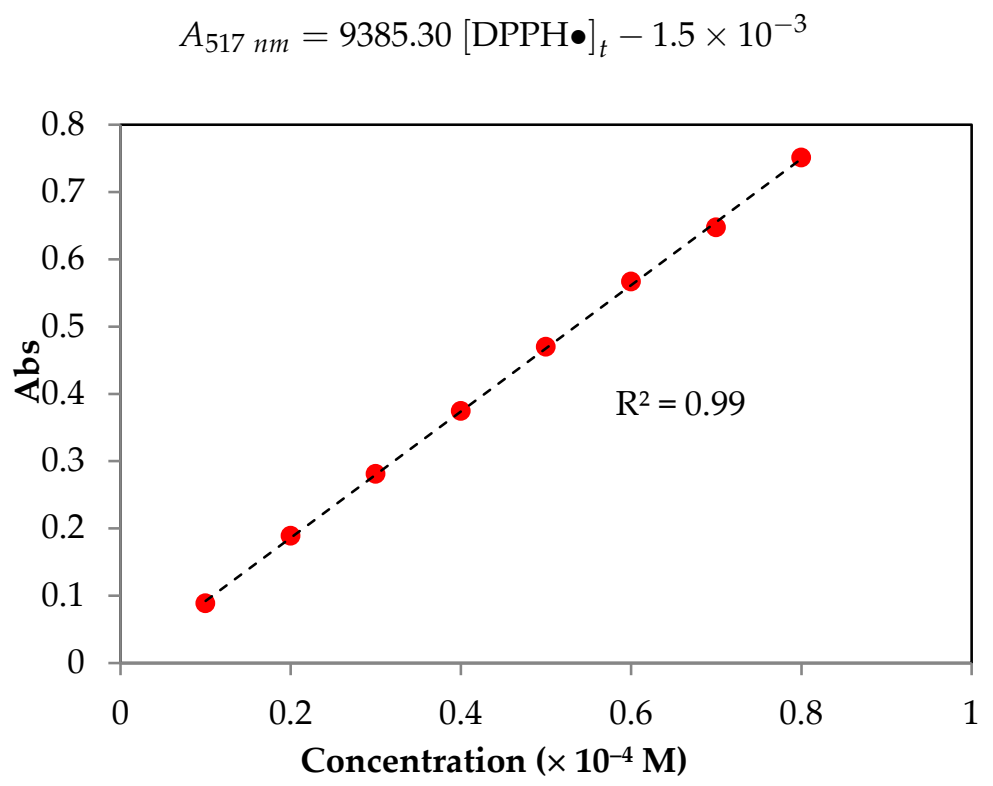

Figure 4. Calibration curve of DPPH solution.

The percentage of remaining DPPH• at steady state was calculated using the formula in Equation (10):

$$
\% \text { DPPH• } \bullet_{r e m}=\frac{A_{f}}{A_{0}} \times 100
$$

where DPPH $\bullet_{\text {rem }}$ is the percentage of remaining DPPH• at steady state, while $A_{0}$ and $A_{f}$ are the initial and final absorbance of DPPH• at $517 \mathrm{~nm}$.

\section{Conclusions}

In this study, the antiradical efficiency (AE) and rate constant of ferulate-based protic ionic liquids (PILs) have been successfully studied using DPPH free radical assay to determine the kinetic behavior. Based on the results obtained, the AE class has changed from low to medium for 2BAEF, 3DMAPF and 3DEAPF, which was due to the strong HAT and ET on the cation structure of PILs that helped to increase the scavenging of DPPH•. Besides, these three PILs also demonstrated a remarkably higher kinetic reaction with the $k_{2}$ values of $164.17,242.84$ and $244.73 \mathrm{M}^{-1} \mathrm{~s}^{-1}$, respectively. The fast HAT and ET reaction mechanisms occurred as more substituents of alky group were present on the nitrogen atom that weakens the interaction of ion-pairs; thus strong and effective of antioxidant activity of the synthesized PILs was observed. Therefore, the synthesized of PILs with a bulkier and larger cation structure could be a good potential DPPH• scavenger for antioxidant activity. 
Supplementary Materials: Figures S1-S6: Extrapolation graph for EC F0 $_{50}$ of F and synthesized PILs, Figures S7-S12: Extrapolation graph for TEC 50 of FA and synthesized PILs.

Author Contributions: N.A.A. conceived, designed and performed the experiments; N.A.A. and K.J. analyzed the data; K.J., A.R., N.A.G., H.A. and L.W.L. contributed reagents/materials/analysis tools/software; N.A.A. and K.J. wrote the paper; all authors read and approved the final manuscript.

Funding: This research was funded by Short Term Internal Research Fund (STIRF 0153AA-F21) Universiti Teknologi PETRONAS. Nur Afiqah Ahmad acknowledges the UTP Graduate Assistantship (GA) scheme, Universiti Teknologi PETRONAS.

Conflicts of Interest: The authors declare no conflict of interest.

\section{References}

1. Bravo, L. Polyphenols: Chemistry, dietary sources, metabolism, and nutritional significance. Nutr. Rev. 1998, 56, 317-333. [CrossRef] [PubMed]

2. Laura, A.; Alvarez-Parrilla, E.; Gonzalez-Aguilar, G.A. Fruit and Vegetable Phytochemicals: Chemistry, Nutritional Value and Stability, 1st ed.; John Wiley \& Sons: Ames, IA, USA, 2009; pp. 336-340.

3. Ghasemzadeh, A.; Ghasemzadeh, N. Flavonoids and phenolic acids: Role and biochemical activity in plants and human. J. Med. Plants Res. 2011, 5, 6697-6703. [CrossRef]

4. Machu, L.M.; Ladislava, V.A.; Jarmila, O.; Jana, M.; Jiri, S.; Jiri, J. Phenolic content and antioxidant capacity in algal food products. Molecules 2015, 20, 1118-1133. [CrossRef] [PubMed]

5. Shahidi, F.; Ambigaipalan, P. Phenolics and polyphenolics in foods, beverages and spices: Antioxidant activity and health effects-A review. J. Funct. Foods 2015, 18, 820-897. [CrossRef]

6. De los Ángeles Fernández, M.; Espino, M.; Gomez, F.J.; Silva, M.F. Novel approaches mediated by tailor-made green solvents for the extraction of phenolic compounds from agro-food industrial by-products. Food Chem. 2018, 239, 671-678. [CrossRef] [PubMed]

7. Yang, Z.; Guo, Z.; Xu, X. Enzymatic lipophilisation of phenolic acids through esterification with fatty alcohols in organic solvents. Food Chem. 2012, 132, 1311-1315. [CrossRef]

8. Uysal, A.; Lazarova, I.; Zengin, G.; Gunes, Z.; Aktumsek, A.; Gevrenova, R. New Perspectives on Asphodeline lutea from Bulgaria and Turkey: Anti-mutagenic, Anti-microbial and Anti-methicillin Resistant Staphylococcus aureus (MRSA) Activity. Br. J. Pharmaceut. Res. 2016, 10, 1-10. [CrossRef]

9. Sharifi-Rad, M.; Tayeboon, G.S.; Miri, A.; Setzer, W.N.; Falah, F.; Kuhestani, K.; Tahanzadeh, N. Mutagenic, antimutagenic, antioxidant, anti-lipoxygenase and antimicrobial activities of Scandix pecten-veneris. Cell. Mol. Biol. 2016, 62, 8-16.

10. Spilioti, E.; Jaakkola, M.; Tolonen, T.L.; Maija, V.; Vesa, C.; Ioanna, K.; Eva, K.; Sofia, M. Phenolic acid composition, antiatherogenic and anticancer potential of honeys derived from various regions in Greece. PLoS ONE 2014, 9, 94860. [CrossRef]

11. Daniel, M. Medicinal Plants: Chemistry and Properties; CRC Press: Boca Raton, FL, USA, 2016.

12. Robbins, R.J. Phenolic acids in foods: An overview of analytical methodology. J. Agric. Food Chem. 2003, 51, 2866-2887. [CrossRef]

13. Kikugawa, M.; Tomoaki, I.; Hideshi, S. Ferulic acid and its water-soluble derivatives inhibit nitric oxide production and inducible nitric oxide synthase expression in rat primary astrocytes. Biosci. Biotechnol. Biochem. 2017, 81, 1607-1611. [CrossRef] [PubMed]

14. Ramawat, K.G.; Mérillon, J.M. Phytochemistry, Botany and Metabolism of Alkaloids, Phenolics and Terpenes, Natural products; Springer: Berlin, Germany, 2013.

15. Li, C.; Li, J.B. Preparation of chitosan-ferulic acid conjugate: Structure characterization and in the application of pharmaceuticals. Int. J. Biol. Macromol. 2017, 105, 1539-1543. [CrossRef] [PubMed]

16. Kumar, N.; Pruthi, V. Potential applications of ferulic acid from natural sources. Biotechnol. Rep. 2014, 4, 86-93. [CrossRef] [PubMed]

17. Boz, H. Ferulic Acid in Cereals-A Review. Czech J. Food Sci. 2015, 33, 1-7. [CrossRef]

18. Nankar, R.; Prabhakar, P.; Doble, M. Hybrid drug combination: Combination of ferulic acid and metformin as anti-diabetic therapy. Phytomedicine 2017, 37, 10-13. [CrossRef] [PubMed]

19. Piotrowski, J.S.; Lu, F.; Kabbage, M.; Ralph, J.; Landick, R.C. Antimicrobial Ferulic Acid Derivatives and Uses Thereof. U.S. Patents 20150313221A1, 2 May 2014. 
20. Winkler-Moser, J.K.; Hwang, H.S.; Bakota, E.P.; Debra, A. Synthesis of steryl ferulates with various sterol structures and comparison of their antioxidant activity. Food Chem. 2015, 169, 92-101. [CrossRef] [PubMed]

21. Alam, M.N.; Bristi, N.J.; Rafiquzzaman, M. Review on in vivo and in vitro methods evaluation of antioxidant activity. Saudi Pharm. J. 2013, 21, 143-152. [CrossRef]

22. Apak, M.R.; Guclu, K.; Ozyurek, M.; Bener, M.; Martinez, E.; Callewaert, D. Optical Sensor-Based Cupric Reducing Antioxidant Capacity (CUPRAC) Assay. U.S. Patents 8912004B2, 24 April 2011.

23. Ioannone, F.; Di Mattia, C.D.; De Gregorio, M.; Sergi, M.; Serafini, M.; Sacchetti, G. Flavanols, proanthocyanidins and antioxidant activity changes during cocoa (Theobroma cacao L.) roasting as affected by temperature and time of processing. Food Chem. 2015, 174, 256-262. [CrossRef]

24. Watanabe, M.; Watanabe, T.; Watanabe, H. Method for Producing Oyster Meat Essence Containing Large Amount of Antioxidants Having High Antioxidative Power and High ORAC Value. U.S. Patents 9943553B2, 11 April 2011.

25. Niki, E. Assessment of antioxidant capacity in vitro and in vivo. Free Radical Biol. Med. 2010, 49, 503-515. [CrossRef]

26. Nenadis, N.; Tsimidou, M. Observations on the estimation of scavenging activity of phenolic compounds using rapid 1, 1-diphenyl-2-picrylhydrazyl (DPPH•) tests. J. Am. Oil Chem. Soc. 2002, 79, 1191. [CrossRef]

27. Rajan, V.K.; Muraleedharan, K. A computational investigation on the structure, global parameters and antioxidant capacity of a polyphenol, Gallic acid. Food Chem. 2017, 220, 93-99. [CrossRef] [PubMed]

28. Marxen, K.; Vanselow, K.H.; Lippemeier, S.; Hintze, R.; Ruser, A.; Hansen, U.P. Determination of DPPH radical oxidation caused by methanolic extracts of some microalgal species by linear regression analysis of spectrophotometric measurements. Sensors 2007, 7, 2080-2095. [CrossRef] [PubMed]

29. Diplock, A.T.; Charuleux, J.L.; Crozier-Willi, G.; Kok, F.J.; Rice-Evans, C.; Roberfroid; Marcel Stahl, W.; Vina-Ribes, J. Functional food science and defence against reactive oxidative species. Br. J. Nutr. 1998, 80, S77-S112. [CrossRef] [PubMed]

30. Terpinc, P.; Abramovič, H. A kinetic approach for evaluation of the antioxidant activity of selected phenolic acids. Food Chem. 2010, 121, 366-371. [CrossRef]

31. Apak, R.; Özyürek, M.; Güçlü, K.; Çapanoğlu, E. Antioxidant activity/capacity measurement 2 Hydrogen atom transfer (HAT)-based, mixed-mode (electron transfer (ET)/HAT), and lipid peroxidation assays. J. Agric. Food Chem. 2016, 64, 1028-1045. [CrossRef] [PubMed]

32. Heravi, M.M.; Haghi, B.; Morsali, A.; Ardalan, P.; Ardalan, T. Kinetic study of DPPH scavenging in the presence of mixture of Zinc and Vitamin C as an antioxidant. J. Chem. Health Risks 2012, 2, 6.

33. Sekhon, B.S. Ionic liquids based active pharmaceutical ingredients. Ars Pharm. 2013, 54, 37-44.

34. Czerniak, K.; Biedziak, A.; Krawczyk, K.; Pernak, J. Synthesis and properties of gallate ionic liquids. Tetrahedron 2016, 72, 7409-7416. [CrossRef]

35. Czerniak, K.; Walkiewicz, F. Synthesis and antioxidant properties of dicationic ionic liquids. New J. Chem. 2017, 41, 530-539. [CrossRef]

36. Klejdysz, T.; Łegosz, B.; Czuryszkiewicz, D.; Czerniak, K.; Pernak, J. Biobased Ionic Liquids with Abietate Anion. ACS Sustainable Chem. Eng. 2016, 4, 6543-6550. [CrossRef]

37. Ali, H.M.; Almagribi, W.; Al-Rashidi, M.N. Antiradical and reductant activities of anthocyanidins and anthocyanins, structure-activity relationship and synthesis. Food Chem. 2016, 194, 1275-1282. [CrossRef] [PubMed]

38. Lu, Z.; Nie, G.; Belton, P.S.; Tang, H.; Zhao, B. Structure-activity relationship analysis of antioxidant ability and neuroprotective effect of gallic acid derivatives. Neurochem. Int. 2006, 48, 263-274. [CrossRef] [PubMed]

39. Ancerewicz, J.; Migliavacca, E.; Carrupt, P.A.; Testa, B.; Brée, F.; Zini, R.; Tillement, J.P.; Labidalle, S.; Guyot, D.; Chauvet, M.; Anne, M. Structure-property relationships of trimetazidine derivatives and model compounds as potential antioxidants. Free Radicals Biol. Med. 1998, 25, 113-120. [CrossRef]

40. Villano, D.; Fernández-Pachón, M.S.; Moyá, M.L.; Troncoso, A.M.; García-Parrilla, M.C. Radical scavenging ability of polyphenolic compounds towards DPPH free radical. Talanta 2007, 71, 230-235. [CrossRef]

41. Mishra, K.; Ojha, H.; Chaudhury, N.K. Estimation of antiradical properties of antioxidants using DPPH assay: A critical review and results. Food Chem. 2012, 130, 1036-1043. [CrossRef]

42. Tokuda, H.; Ishii, K.; Susan, M.A.B.H.; Tsuzuki, S.; Hayamizu, K.; Watanabe, M. Physicochemical properties and structures of room-temperature ionic liquids. 3. Variation of cationic structures. J. Phys. Chem. B 2006, 110, 2833-2839. [CrossRef] [PubMed] 
43. Tsuzuki, S. Factors controlling the diffusion of ions in ionic liquids. ChemPhysChem 2012, 13, 1664-1670. [CrossRef] [PubMed]

44. Apak, R.; Capanoglu, E.; Shahidi, F. Measurement of Antioxidant Activity and Capacity: Recent Trends and Applications, 3rd ed.; John Wiley \& Sons: Chichester, UK, 2017.

45. Sanchez, M.C.; Larrauri, J.; Saura, C. A procedure to measure the antiradical efficiency of polyphenols. J. Sci. Food Agric. 1998, 76, 270-276. [CrossRef]

46. Xie, J.; Schaich, K. Re-evaluation of the 2, 2-diphenyl-1-picrylhydrazyl free radical (DPPH) assay for antioxidant activity. J. Sci. Food Agric. 2014, 62, 4251-4260. [CrossRef]

47. Brand-Williams, W.; Cuvelier, M.E.; Berset, C. Use of a free radical method to evaluate antioxidant activity. LWT-Food Sci. Technol. 1995, 28, 25-30. [CrossRef]

48. Bendary, E.; Francis, R.R.; Ali, H.M.G.; Sarwat, M.I.; El Hady, S. Antioxidant and structure-activity relationships (SARs) of some phenolic and anilines compounds. Annals Agric. Sci. 2013, 58, 173-181. [CrossRef]

49. Klein, E.; Matis, M.; Lukeš, V.; Cibulková, Z. The applicability of AM1 and PM3 semi-empirical methods for the study of $\mathrm{N}-\mathrm{H}$ bond dissociation enthalpies and ionisation potentials of amine type antioxidants. Polym. Degrad. Stab. 2006, 91, 262-270. [CrossRef]

50. Lalevée, J.; Allonas, X.; Fouassier, J.P. N-H and $\alpha(\mathrm{C}-\mathrm{H})$ bond dissociation enthalpies of aliphatic amines. J. Am. Chem. Soc. 2002, 124, 9613-9621. [CrossRef] [PubMed]

51. Joshi, R.; Ghanty, T.K.; Mukherjee, T. Substituent effect on ionization potential, O-H bond dissociation energy and intra-molecular hydrogen bonding in salicylic acid derivatives. J. Mol. Struct. THEOCHEM 2010, 948, 47-54. [CrossRef]

52. Foti, M.C.; Daquino, C.; Geraci, C. Geraci, Electron-transfer reaction of cinnamic acids and their methyl esters with the DPPH• radical in alcoholic solutions. J. Org. Chem. 2004, 69, 2309-2314. [CrossRef] [PubMed]

Sample Availability: Samples of the compounds ferulate- based PILs are available from the authors.

(C) 2018 by the authors. Licensee MDPI, Basel, Switzerland. This article is an open access article distributed under the terms and conditions of the Creative Commons Attribution (CC BY) license (http://creativecommons.org/licenses/by/4.0/). 